\title{
Analysis of Digital Self-Presentation Practices and Profiles of Spanish Adolescents on Instagram and TikTok
}

\author{
María José Hernández-Serrano ${ }^{1}$, Barbara Jones $^{2}$ (D), Paula Renés-Arellano ${ }^{3}$ and Rosalynn A. \\ Campos Ortuño ${ }^{1}$
}

${ }^{1}$ Department of Theory and History of Education, University of Salamanca, Spain

${ }^{2}$ The University of Manchester, United Kingdom

${ }^{3}$ University of Cantabria, Spain

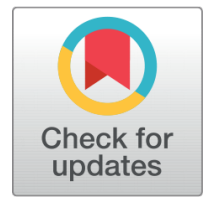

Received 2021-06-24

Revised 2021-06-29

Accepted 2021-11-02

Published 2022-01-15

\section{Corresponding Author}

María José Hernández-Serrano, mjhs@usal.es

Universidad de Salamanca.

Escuela Universitaria de

Magisterio. Campus Viriato.

Avda Cardenal Cisneros, 34,

49022 Zamora, Spain.

DOI https://doi.org/10.7821/

naer.2022.1.797

Pages: 49-63

Funding: Spanish State

Research Agency, Spain

(Award:PGC2018-097884-B-I00)

Distributed under

CC BY-NC 4.0

Copyright: ( ) The Author(s)

\section{ABSTRACT}

This study analyses self-presentation practices and profiles among Spanish teenagers on Instagram and TikTok. Both of these online spaces prioritise and promote visual publications, are structured to allow feedback on self-presentation, and offer the user filters both to control self-image and to target specific audiences. Three research questions guided the methodological process for the twofold analysis of self-presentation practices on social networks: an exploratory factor analysis to identify latent factors among these practices; and a descriptive analysis of the profiles identified by gender and age. Results indicate that adolescents' self-presentation practices were related to three different factors: social validation; authenticity; and image control. One of the most outstanding results is that self-presentation practices could be less guided by social feedback, since the number of followers or likes was irrelevant for most adolescents, and that adolescents increasingly tend to be guided by innovative predispositions of truthfulness. In turn, conclusions suggest that teens need to be equipped with suitable self-representation practices for safe and sustainable identity narratives on social networks, since the global COVID-19 pandemic has exponentially increased both the usage and the time spent on social networking sites, enlarging the availability of spaces for adolescents to express themselves and build their identities through different self-representation practices.

Keywords ADOLESCENTS, DIGITAL IDENTITY, SELF-PRESENTATION, INSTAGRAM, TIKTOK

\section{INTRODUCTION}

The ongoing global pandemic, whilst consolidating trends and uses, has generated an extraordinary exponential growth worldwide of activity on the internet and social networking (SN) platforms: more than half of the world now uses social media, of those users, 316 million new users have come online during the last 12 months (Datareportal, 2021). The

\section{OPEN ACCESS}


growth experienced by a variety of SN platforms has resulted in multi-networking with users turning to particular platforms for specific needs. These platforms have offered young people opportunities for the presentation of new lifestyles as well as for behavioural changes in interaction, publishing and consumption. In the case of Spain, where this study took place, $80 \%$ of the total population is already on at least one social network (WeAreSocial, 2021) and $47.7 \%$ of children below 15 years of age use Instagram, TikTok ranking second with 37.7\% (Statista, 2021).

A range of studies have illustrated how adolescents have already become a generation of connected users (García-Umaña \& Tirado-Morueta, 2018; Huang \& Su, 2018; MaloCerrato, Martín-Perpiñá, \& Viñas-Poch, 2015; Vidales-Bolaños \& Sádaba, 2017) with intensive usage in their preferred SN platforms, such as Instagram or TikTok (Brailovskaia, Schillack, \& Margraf, 2020; Carpenter, Morrison, Craft, \& Lee, 2020; Dilon, 2020; Fondevila-Gascón, Gutiérrez-Aragón, Copeiro, Villalba-Palacín, \& Polo-López, 2020; Lázaro-Niso, 2020; Torrecillas-Lacave, Vázquez-Barrio, Suárez, \& Fernández-Martínez, 2020; Zuo \& Wang, 2019). From this evidence, our study examines the specific intensive use of these SN platforms by adolescents as spaces that enable them to express their identity. Together with motives for communication and socialisation, the younger generations see SNs as opportunities to convey and construct their identities (Albarello, Crocetti, \& Rubini, 2018; Bell, 2019; Carpenter et al., 2020; Ditchfield, 2020; Yang, Holden, \& Carter, 2018). Through the different self-presentation practices available on SNs, adolescents learn to increase the possibilities of experiencing their identity expression, since social expositions and validation are expanded to wider audiences and consequently supply wider feedback.

This paper firstly considers theories of self-presentation in adolescence (among which stand out those of Goffmand, 1959; Erikson, 1959; Boyd, 2007; Gee, 1999; and Davies, 2014) in order to analyse to what extent self-presentation practices, norms and techological affordances provided by SN platforms questions developmental factors, and which of them differ from how adolescents' online behaviour compared to the offline behaviour. Social networking not only enlarges the chances to explore and deploy different identities but also encourages users to be concerned with authenticity and commitment to sustainable images and identities. Secondly, the technological affordances offered by these two SN platforms which enjoy so much popularity among adolescents are considered regarding the different selfpresentation practices promoted. Then, data from a sample of adolescents are examined to explore practices and profiles associated with the intensive users of both SN platforms, some educational implications in line with responsible uses by adolescents being finally raised to conclude.

\subsection{Self-Presentation Theories for Online Identity Construction in Adolescence}

Self-presentation refers to practices used to convey an impression of the self by controlling personal information to represent a preferred self-image (Goffman, 1959). The idea of constructing and sustaining a way of being and belonging during adolescence may be associated with subjective feelings and the experience of social connections and interactions, 
in line with the discourse identity theory (Gee, 1999). As noted by Kay (2018), the relevance of social context for adolescent self-presentation becomes expanded and heightened online; the sense of selfhood not only develops through what individuals subjectively feel or anticipate about themselves but also because of the ways in which online social learnings, socialisations and transactions permanently affect this self-presentation while inhabiting roles, or positions that matter to them, or their social group (Mclay \& Renshaw, 2019). In this sense, Davis $(2013,2014)$ described how received feedback and validation from others online are likely to affect clarity and judgement in choosing self-expression practices. Social approval is seen at this age as one of the main goals for self-presentation online which determine either identity exploration and commitment (Boyd, 2007; Davis, 2014). Social position and degrees of social interaction are perceived as status markers of social belonging (Marcia, 2002) when it comes to the confirmation of one's own identity by other people, with cues about what seems socially appropriate or is observed in others (Davis, 2013; Herring \& Kapidzic, 2015).

Besides the social factors, the preferences and the deployment of different selfpresentation practices could also be influenced by situational or contextual conditions which invite adolescents to opt for a different identity performance (Yang et al., 2018). The architectural configurations of digital platforms will most probably also be offering opportunities for identity construction, such as editable affordances to perfect a user's identity profile (Ditchfield, 2020), tactics to exploit likeability (Hong, Jahng, Lee, \& Wise, 2020) or the self-promotion of only the positive aspects of user identity (Scott \& Fullwood, 2020). Ideal and favourable presentations of themselves correspond to another main goal of self-presentation, described as image control (Omarzu, 2000; Valkenburg \& Peter, 2011) or management of the impression caused (Herring \& Kapidzic, 2015) from which projections of real or fake identities can be amplified on digital spaces. This control is operated through various online practices such as opportunities to present multiple and different identities on several platforms, or via different profiles on a single platform, as well as the possibilities to filter the audiences who can see those personal profiles or publications.

Management and control possibilities for online image impression, together with anonymity, are recognized in some studies carried out over the last decades to be related to risks and fake identities. The overused focus on risks to youth online lead to a certain level of moral panic that has subsequently been criticised (Boyd, 2007). In this vein, Turkle's vision of social networks as "social laboratories" to experiment with a multiplicity of selves has challenged researchers to reconsider whether the current younger generations are taking less and less advantage of the refinement or polished possibilities available online (Davis, 2014). Nowadays, authenticity values could prevail over multiplicity and fake self-presentations, since excessive or drastic changes and versions have started to be culturally rejected by peers (Hong et al., 2020; Mascheroni, Vincent, \& Jimenez, 2015). As a result, adolescents might begin to prefer non-elaborated versions of themselves, extending or connecting their offline identity to overlap in the context of their online spaces. Users are looking for consistency, based on a sustained standard in self-image, which entails an innovative commitment-making during the process of self-presentation (Crocetti, Rubini, 
Branje, Koot, \& Meeus, 2016). More importantly, this commitment could be guided as an inner goal showing an authentic sense of identity (Ditchfield, 2020), peer-guided by dealing with others' reactions (Albarello et al., 2018) or encouraged by technologies, since some of them explicitly ask users to provide truthful personal information (Herring \& Kapidzic, 2015).

\subsection{Self-Presentation Practices of Adolescents on Instagram and TikTok}

Even though there are similar features, such as prioritising visual publications (posts), each SN can promote or limit different practices for users' self-presentation; this study refers to the most popular SNs among Spanish adolescents which are described as follows.

Instagram is a popular social networking application designed to share photos and videos online through which they can be edited using filters and digital retouching (WeAreSocial, 2021), thus offering control over self-presentation. The prioritisation of visual content not only promotes aesthetic values but also shows different lifestyles through posts about everyday life. The Stories Option allows the posting of content that disappears the next day, consequently encouraging the audience's frequent connection to keep up to date with the content posted by the followers of this social network. It facilitates control of selected audiences, turning this application into an attractive tool for young people (Arriaga, Marcellán, \& Reyes, 2016). According to Marcelino (2015) , young people value Instagram because it conveys a sense of freedom of expression. Likewise, the reasons young people may prefer to use this application include: compilation of important life situations, social interaction, gossip through anonymity and self-expression (E. Lee, Lee, Moon, \& Sung, 2015; Prades \& Carbonell, 2016). Remarkably, some studies refer to personal gratification derived from sharing photographs and feeling valued when they are positively received, by creating common interests (Ting, Wong, Run, \& Choo, 2015).

TikTok stands out as another of the most popular social networks among adolescents. It offers them the possibility to design, edit and share short videos, to which filters can be applied, and which can be accompanied by songs, predominantly current music trends, but also other genres. Simple and intuitive, this application promotes creativity in self-presentations, additionally inspiring others to copy or beat it, by means of challenges (Lázaro-Niso, 2020). It allows setting up accounts restricted to private audiences, approving or rejecting followers' access to certain personal content, and enabling users to control who can view and rate posts. According to Zuo and Wang (2019), during the process of constructing their own identity, Tik Tok users understand and reflect on themselves because of the processes of recognition in others, of what they think and how they are appearing. Moreover, their own identity and self-representation are validated and complemented through the interaction with other users. TikTok users also divide themselves into groups based on their interests, initiate challenges suggested by the platform and meet with groups who share similar hobbies, thus strengthening the sense of group identity and belonging. 


\subsection{Purpose of the Study and Research Questions}

The aim sought with this paper consists in examining how adolescents are harnessing the digital opportunities provided by SN platforms for self-presentation. Analysis is offered on self-presentation practices and profiles in two of the most popular SN platforms among Spanish adolescents: Instagram and TikTok. Our interest is justified by the fact that both digital spaces are structured to promote different practices for presenting one's image, in addition to allowing feedback for and by users and offering the chance to monitor both selfpresentation and audiences. Three Research Questions were defined to achieve the aforesaid aim:

- RQ1: What are the most frequent self-presentation practices of adolescents on Instagram and (on) TikTok?

- RQ2: Can these self-presentation practices on Instagram and TikTok be related to differential profiles?

- RQ3: If the answer to RQ2 is positive, do significant differences by age or gender exist among Instagramers' and Tiktokers' profiles?

\section{METHODS}

Within the context of a national research project a questionnaire was designed in four dimensions to measure the online adolescent interactions aimed at their identity building and the hyperconnection risks, for which purpose we examined variables from three dimensions: 1) socio-demographic variables (age, gender); 2) online connection scenarios and uses (social networks); and 3) ten self-presentation practices. The operationalisation of these dimensions relied on concepts and variables that had emerged in a previous qualitative phase (Muñoz-Rodríguez, Fincias, González, \& Hueso, 2020) using Likert-type scales and dichotomous questions. After a pilot-test, a 19-item final questionnaire was administrated online during November 2020, obtaining a satisfactory index for internal consistency (Cronbach's Alpha $=0.713)$.

The final sample consisted of 2,066 students (with 57.2 of females and $42.8 \%$ of males) aged 12 to 18 and grouped for this study into three ranges: 1) 12-to-14-year-olds with the highest proportion (39.2\%); 2) 15-to-16-year-olds (38.5\%); and 3) 17-to-18-year-olds (22.3\%).

The procedure to select user types was based on section 2) in the questionnaire; for each $\mathrm{SN}$, participants were asked to specify whether they made an 'intensive use' (on a continuous basis to post videos, photos or comments); a 'limited use' (less frequently and to review information from others); or 'no use' at all. Firstly, adolescents were divided into Instagram users $(\mathrm{n}=1,754 ; 84.9 \%$ from $\mathrm{N}=2,066)$ and TikTok users $(\mathrm{n}=1,388 ; 67.2 \%)$. Then, for the selection of intensive users, for Instagram $n=1,124,54.4 \%$ were intensive users and $30.5 \%$ limited, whereas for TikTok $n=665,32.2 \%$ were intensive users and 35\% limited. Regarding to RQ1, and seeking to verify whether the practices on these two SNs are different or similar, separated analyses were run with the two subsamples of intensive users. 
As for RQ2, according to López-Aguado and Gutiérrez-Provecho (2019), an Exploratory Factor Analysis (EFA) using the IBM SPSS Amos v.26 software served to identify unobservable latent factors in the set of variables that described the "self-presentation practices" (with 10 items) which were understood to be theoretically related according to the previours studies. Factors would describe intensive users' practices by replicating the EFA process on both platforms. Finally, profiles were identified to answer RQ3 in terms of gender and age-based differences.

\section{RESULTS}

In order to compare the data corresponding to the self-presentation practices for the two selected SNs (for RQ1) percentages of agreement were arranged in Table 1, in which intensive users practices are positioned with similar behaviours or attitudes (see Table 1). Examples include the following: adolescents do not care about the number of followers (item 2), likes or views (3). They also share the most realistic versions of themselves (9) with real photos (4), from which they prefer to be recognised (5). Other identified practices with more variability divide the sample into two halves: those who have different profiles (1), share real personal information (6) and forward/share other posts instead of publishing their own content (8); and the ones who could behave otherwise. Finally, in the items referring to practices of filtering, either their version of the self/themselves (10) or the audiences for which they publish personal content (7), two thirds of the sample agreed that this was not a common practice. No statistically significant differences appeared between practices found for Instagram and TikTok intensive users.

For RQ2, a first factorial analysis was run with the 10 items measuring self-presentation practices that covered the total sample $\mathrm{N}=2,066$ and sought to explain the maximum percentage of variance observed in each item from a smaller number of components. The factorial analysis was replicated in the two subsamples of Instagram and TikTok intensive users, considering the different technological configurations used in each SN to provide different self-presentation practices. The KMOs of all three groups turned out to be adequate and presented a significant level of sphericity for every sample ( $p$ less than 0.001) (see Table 2), which allowed us to confirm the adequacy of the exploratory process.

The principal components method with orthogonal rotation (varimax) and Kaiser normalisation was initially applied to the main sample, then to Instagramers, and finally to TikTokers. Firstly, in the main sample, three components were selected according to the total explained variance of 59.760\% considered as an adequate proportion (Hair, Anderson, Tatham, \& Black, 1999). In an effort to avoid rotational indeterminacies and to favour the subsequent interpretation of the factors (Lorenzo-Seva \& Ferrando, 2013), it was deemed appropriate to apply the independent cluster basis (I-CB) condition (Mcdonald, 2005), which recommends that each factor should be defined by at least two items per factor if those items are theoretically related. Lorenzo-Seva and Ferrando (2013) also advise researchers to distinguish the major common factors to retain for more interpretability, bearing in mind to avoid those items whose factor loadings had not exceeded the value of 0.40 (Nunnally \& 
Table 1 Percentages of agreement for "self-presentation practices" among intensive users of Instagram and TikTok

\begin{tabular}{|c|c|c|c|c|c|}
\hline & & \multicolumn{2}{|c|}{ Disagree } & \multicolumn{2}{|c|}{ Agree } \\
\hline & & $f$ & $\%$ & $f$ & $\%$ \\
\hline \multirow[t]{2}{*}{ 1. I have several profiles } & Instagram & 598 & 53.2 & 526 & 46.8 \\
\hline & TikTok & 344 & 51.7 & 321 & 48.3 \\
\hline \multirow[t]{2}{*}{ 2. The number of followers matters to me } & Instagram & 951 & 84.6 & 173 & 15.4 \\
\hline & TikTok & 563 & 84.7 & 102 & 15.3 \\
\hline \multirow[t]{2}{*}{ 3. The number of likes or views matters to me } & Instagram & 963 & 85.7 & 161 & 14.3 \\
\hline & TikTok & 574 & 86.3 & 91 & 13.7 \\
\hline \multirow[t]{2}{*}{ 4. I use my real photo on my social networks } & Instagram & 269 & 23.9 & 855 & 76.1 \\
\hline & TikTok & 145 & 21.8 & 520 & 78.2 \\
\hline \multirow[t]{2}{*}{ 5. I prefer to use real data or photos to be recognised } & Instagram & 251 & 22.3 & 873 & 77.7 \\
\hline & TikTok & 142 & 21.4 & 523 & 78.6 \\
\hline \multirow[t]{2}{*}{ 6. I share real personal information (photos, location(s), hobbies) } & Instagram & 592 & 52.7 & 532 & 47.3 \\
\hline & TikTok & 330 & 49.6 & 335 & 50.4 \\
\hline \multirow[t]{2}{*}{ 7. I filter contacts to control who can see my information } & Instagram & 778 & 69.2 & 346 & 30.8 \\
\hline & TikTok & 451 & 67.8 & 214 & 32.2 \\
\hline \multirow[t]{2}{*}{ 8. I share what others post } & Instagram & 615 & 54.7 & 509 & 45.3 \\
\hline & TikTok & 359 & 54.0 & 306 & 46.0 \\
\hline \multirow[t]{2}{*}{ 9. I share myself just like in real life } & Instagram & 263 & 23.4 & 861 & 76.6 \\
\hline & TikTok & 155 & 23.3 & 510 & 76.7 \\
\hline \multirow[t]{2}{*}{ 10. I use filters to give a better version of myself } & Instagram & 740 & 65.8 & 384 & 34.2 \\
\hline & TikTok & 431 & 64.8 & 234 & 35.2 \\
\hline
\end{tabular}

Note: Sample $\mathrm{n}$ Global $=2.066 ; \mathrm{n}$ Instagram $=1.124 ; \mathrm{n}$ TikTok $=665 ;{ }^{\star} \%=$ On social network

Table 2 KMO and Bartlett's tests for the EFA

\begin{tabular}{lllll} 
& & All SNs & Instagram & TikTok \\
\hline $\begin{array}{l}\text { Kaiser-Meyer-Olkin } \\
\text { measure of sampling } \\
\text { adequacy }\end{array}$ & 0.669 & 0.669 & 0.679 \\
$\begin{array}{l}\text { Bartlett's sphericity test } \\
\end{array}$ & Aprox. $X^{2}$ & 241722810596156,000 & 127869895271685,000 & 764834872500745,000 \\
& $d f$ & 28 & 28 & 28 \\
& Sig. & 0.000 & 0.000 & 0.000 \\
\hline
\end{tabular}

Note: Total Sample N = 2.066; Instagram N =1.124; TikTok N=665

Bernstein, 1994). Table 3 presents both the items and their loads; the item "I share myself just like in real life" (9) was the only one that gave factor loadings on one factor (Global= 0.836; Instagram $=0.889$; TikTok=0.914). Since the factor loadings of the item "I use filters to give a better version of myself" (10) were lower than 0.40 on all the networks, both items were eliminated, reducing into 8 items, with same considerations when replying for the two samples of Instagramers and TikTokers (see Table 3).

Three factors were obtained for the global sample (Table 3) thus stating considerations raised in the theoretical framework. The first factor groups together the variables that indicate the use of real personal information on social networks, not only data but also photographs, hobbies and locations, which can be named as actions and practices to achieve 
Table 3 Factorial loads in the global sample $(n=2,066)$

\begin{tabular}{|c|c|c|c|}
\hline Items & Component & & \\
\hline & Factor 1 & Factor 2 & Factor 3 \\
\hline & Authenticity & Social & Control \\
\hline $\begin{array}{l}\text { 5. I prefer to use real data or photos to } \\
\text { be recognised }\end{array}$ & 0.857 & 0.003 & -0.009 \\
\hline $\begin{array}{l}4 \text {. I use my real photo on my social net- } \\
\text { works }\end{array}$ & 0.838 & 0.067 & 0.140 \\
\hline $\begin{array}{l}\text { 6. I share my real personal information } \\
\text { (photos, locations, hobbies) }\end{array}$ & 0.533 & 0.147 & 0.502 \\
\hline $\begin{array}{l}\text { 2. The number of followers matters to } \\
\text { me }\end{array}$ & 0.054 & 0.864 & 0.062 \\
\hline $\begin{array}{l}\text { 3. The number of likes or views matters } \\
\text { to me }\end{array}$ & 0.049 & 0.860 & 0.078 \\
\hline 8. I share what others publish & 0.040 & 0.050 & 0.716 \\
\hline $\begin{array}{l}\text { 7. I filter contacts to control who can } \\
\text { see my information }\end{array}$ & 0.011 & -0.059 & 0.611 \\
\hline $\begin{array}{l}\text { 1. I have several profiles on one social } \\
\text { network }\end{array}$ & 0.174 & 0.217 & 0.534 \\
\hline Cronbach's alpha & $\alpha=0.675$ & $\alpha=0.691$ & $\alpha=0.334$ \\
\hline
\end{tabular}

Note: Extraction method: Principal Components Analysis. Rotation method: Varimax with Kaiser normalisation. Rotation has converged in 3 iterations.

"authenticity" in the self-presentation (Herring \& Kapidzic, 2015). In turn, the second factor brings together two variables related to the social validation obtained after the presentation (Davis, 2014; Mclay \& Renshaw, 2019) according to the relevance of peer validation in adolescence (Boyd, 2007) and referring number of Likes and followers in SNs, this factor was tagged as online "social approval". The last factor gathers the actions of low real selfpresentation in SNs, when adolescents mainly forward what others post, filter audiences and recognise to have several profiles to probably present themselves in multiple ways; and was tagged as "image control" in their self-presentation practices (Ditchfield, 2020; Scott \& Fullwood, 2020) for different aims, such as the exploration of fake identities or impression management. Although this last factor obtained a lower Cronbach's alpha test, it was included for its connection to the theoretical groundwork explored related to "image control" and for internal consistency purposes since the three factors in entirety resulted in acceptable values. Noteworthily, the two items excluded in the factorial analysis could be representative for Factor 1 (item 9), and for Factor 3 (item 10). No clear association were present, though, and this inconsistency could indicate adolescents desirability in their answers.

When applying factorial analysis in the subsamples of intensive users for Tiktokers and Instagramers (see Table 4), the same three factors described for the global sample appeared. However, two items related to self-presentation practices of control (7, filtering audiences) and authenticity practices ( 6 , sharing real personal information) were not included according to previously made decisions on the grounds of dissimilar factor loading representation; after that, the total variance explained increased up to $71.45 \%$ for Instagram and $71.70 \%$ for TikTok, from values of $57 \%$ and $59 \%$, respectively. Factor 3 is the same (image control) in 
these analyses; nevertheless, Factor 2 is the obtained first in the global sample (authenticity), and Factor 1 is the second (social approval).

Table 4 Factorial loads for TikTok and Instagram subsamples

Items

Component Instagram

Component TikTok

\begin{tabular}{|c|c|c|c|c|c|c|}
\hline & $\begin{array}{c}\text { Factor } 1 \\
\text { Social }\end{array}$ & $\begin{array}{c}\text { Factor } 2 \\
\text { Auth. }\end{array}$ & $\begin{array}{l}\text { Factor } 3 \\
\text { Control }\end{array}$ & $\begin{array}{c}\text { Factor } 1 \\
\text { Social }\end{array}$ & $\begin{array}{c}\text { Factor } 2 \\
\text { Auth. }\end{array}$ & $\begin{array}{r}\text { Factor } 3 \\
\text { Control }\end{array}$ \\
\hline $\begin{array}{l}\text { 3. The number of likes or views } \\
\text { matters to me }\end{array}$ & 0.861 & & & 0.854 & & \\
\hline $\begin{array}{l}\text { 2. The number of followers } \\
\text { matters to me }\end{array}$ & 0.869 & & & 0.851 & & \\
\hline $\begin{array}{l}\text { 5. I prefer to use real data or } \\
\text { photos to be recognised }\end{array}$ & & 0.884 & & & 0.868 & \\
\hline $\begin{array}{l}\text { 4. I use my real photo on my } \\
\text { social networks }\end{array}$ & & 0.835 & & & 0.862 & \\
\hline $\begin{array}{l}\text { 8. I share what others post more } \\
\text { than own content }\end{array}$ & & & 0.821 & & & 0.86 \\
\hline $\begin{array}{l}\text { 1. I have several profiles on one } \\
\text { social network }\end{array}$ & & & 0.732 & & & 0.687 \\
\hline Cronbach's alpha & $\alpha=0.680$ & $\alpha=0.676$ & $\alpha=0.391$ & $\alpha=0.666$ & $\alpha=0.688$ & $\alpha=0.399$ \\
\hline
\end{tabular}

Note: Extraction method: principal components analysis. Rotation method: Varimax with Kaiser normalisation. Rotation has converged in 3 iterations.

With regard to RQ3, the factors obtained in Table 4 were saved as new variables, and values for each participant were separated into three levels (low, medium, high) according to previous studies (García-Umaña \& Tirado-Morueta, 2018) with the aim of analysing profiles by age and gender.

In Table 5, no significant age-based differences emerged. Higher percentages remain in the low category for Factor 1 social approval in both SNs, which means that this could not be a prerequisite, in general, for online adolescent self-presentation. The highest percentage corresponded to the age range of 17-to-18-year-olds on TikTok, again in the lower levels (81.2\%). Even percentages of medium and low were inferior and it is noticeable that for adolescents aged 12-to-14 (early adolescence) the percentages might indicate that they are more concerned with social feedback and approval in their self-presentation practices on both SNs. Regarding Factor 2 authenticity, percentages varied, though presenting higher levels on TikTok, with medium levels being recorded for all age ranges on Instagram. This means that presenting as authentic probably depends on the respective SN's affordances. Nonetheless, the concentration of higher percentages in the medium and higher levels for all age ranges could indicate that culturally, adolescents are starting to consider more realistic presentations on SNs. Finally, for Factor 3 image control, the highest percentages appeared in the lower levels, with slightly higher levels for the age range of 17-to-18 years, which means that image control, such as having different profiles on SNs, is bound to decrease along the age range to both Instagramers and TikTokers.

According to Table 6, it can be stated that apparently there were no differences associated with gender. Factor 1 social approval is similarly distributed across the lower level in both genders. However, the higher percentages were found for females in both SNs, which 
Table 5 Factors-values for Instagramers and TikTokers by age

\begin{tabular}{|c|c|c|c|c|c|c|c|c|c|}
\hline & & \multicolumn{4}{|c|}{ Age Ranges Instagram } & \multicolumn{4}{|c|}{ Age Ranges TikTok } \\
\hline & & $12-14$ & $15-16$ & $17-18$ & $\begin{array}{c}\text { Value (sig.; } \\
\text { df) }{ }^{*}\end{array}$ & $12-14$ & $15-16$ & $17-18$ & $\begin{array}{c}\text { Value (sig.; } \\
\quad d f)^{*}\end{array}$ \\
\hline & Low & $\begin{array}{c}346 \\
(78.8 \%)\end{array}$ & $\begin{array}{c}348 \\
(79.6 \%)\end{array}$ & $\begin{array}{c}194 \\
(78.2 \%)\end{array}$ & & $\begin{array}{c}200 \\
(79.1 \%)\end{array}$ & $\begin{array}{c}206 \\
(78.3 \%)\end{array}$ & $\begin{array}{c}121 \\
(81.2 \%)\end{array}$ & \\
\hline \multirow[t]{3}{*}{ Factor 1. Social } & Medium & $\begin{array}{c}58 \\
(13.2 \%)\end{array}$ & $\begin{array}{c}46 \\
(10.5 \%)\end{array}$ & $\begin{array}{c}34 \\
(13.7 \%)\end{array}$ & $\begin{array}{c}2.664 \\
(0.616 ; 4)\end{array}$ & $\begin{array}{c}34 \\
(13.4 \%)\end{array}$ & $\begin{array}{c}32 \\
(12.2 \%)\end{array}$ & $\begin{array}{c}17 \\
(11.4 \%)\end{array}$ & $\begin{array}{c}1,250 \\
(0.870 ; 4)\end{array}$ \\
\hline & High & $35(8.0 \%)$ & $43(9.8 \%)$ & $20(8.1 \%)$ & & $19(7.5 \%)$ & $25(9.5 \%)$ & $11(7.4 \%)$ & \\
\hline & Low & $\begin{array}{c}126 \\
(28.7 \%)\end{array}$ & $\begin{array}{c}144 \\
(33.0 \%)\end{array}$ & $\begin{array}{c}72 \\
(29.0 \%)\end{array}$ & & $\begin{array}{c}61 \\
(24.1 \%)\end{array}$ & $\begin{array}{c}72 \\
(27.4 \%)\end{array}$ & $\begin{array}{c}36 \\
(24.2 \%)\end{array}$ & \\
\hline \multirow[t]{3}{*}{$\begin{array}{l}\text { Factor } 2 . \\
\text { Authenticity }\end{array}$} & Medium & $\begin{array}{c}263 \\
(59.9 \%)\end{array}$ & $\begin{array}{c}240 \\
(54.9 \%)\end{array}$ & $\begin{array}{c}147 \\
(59.3 \%)\end{array}$ & $\begin{array}{c}2.893 \\
(0.576 ; 4)\end{array}$ & $\begin{array}{c}83 \\
(32.8 \%)\end{array}$ & $\begin{array}{c}74 \\
(28.1 \%)\end{array}$ & $\begin{array}{c}42 \\
(28.2 \%)\end{array}$ & $\begin{array}{c}2,234 \\
(0.693 ; 4)\end{array}$ \\
\hline & High & $\begin{array}{c}50 \\
(11.4 \%)\end{array}$ & $\begin{array}{c}53 \\
(12.1 \%)\end{array}$ & $\begin{array}{c}29 \\
(11.7 \%)\end{array}$ & & $\begin{array}{c}109 \\
(43.1 \%)\end{array}$ & $\begin{array}{c}117 \\
(44.5 \%)\end{array}$ & $\begin{array}{c}71 \\
(47.7 \%)\end{array}$ & \\
\hline & Low & $\begin{array}{c}269 \\
(61.3 \%)\end{array}$ & $\begin{array}{c}264 \\
(60.4 \%)\end{array}$ & $\begin{array}{c}160 \\
(64.5 \%)\end{array}$ & & $\begin{array}{c}153 \\
(60.5 \%)\end{array}$ & $\begin{array}{c}145 \\
(55.1 \%)\end{array}$ & $\begin{array}{c}99 \\
(66.4 \%)\end{array}$ & \\
\hline \multirow[t]{2}{*}{ Factor 3. Control } & Medium & $\begin{array}{c}116 \\
(26.4 \%)\end{array}$ & $\begin{array}{c}125 \\
(28.6 \%)\end{array}$ & $\begin{array}{c}67 \\
(27.0 \%)\end{array}$ & $\begin{array}{c}2.975 \\
(0.562 ; 4)\end{array}$ & $\begin{array}{c}68 \\
(26.9 \%)\end{array}$ & $\begin{array}{c}86 \\
(32.7 \%)\end{array}$ & $\begin{array}{c}37 \\
(24.8 \%)\end{array}$ & $\begin{array}{c}5.989 \\
(0.200 ; 4)\end{array}$ \\
\hline & High & $\begin{array}{c}54 \\
(12.3 \%)\end{array}$ & $48(11 \%)$ & $21(8.5 \%)$ & & $\begin{array}{c}32 \\
(12.6 \%)\end{array}$ & $\begin{array}{c}32 \\
(12.2 \%)\end{array}$ & $13(8.7 \%)$ & \\
\hline
\end{tabular}

Note: Instagram $\mathrm{N}=1.124$; TikTok $\mathrm{N}=665 ;{ }^{*} \chi^{2}$

means that social feedback could be less important for them. Regarding Factor 2 authenticity, females once again show the highest percentages on both SNs in the higher and medium levels, which suggests that female users could be more committed to authenticity, especially on TikTok. Finally, the percentages for Factor 3 image control revealed that a majority of intensive users do not care about this, most noticeably among males.

Table 6 Factors-values for Instagramers and TikTokers by gender

\begin{tabular}{|c|c|c|c|c|c|c|c|}
\hline & & \multicolumn{3}{|c|}{ Gender Instagram } & \multicolumn{3}{|c|}{ Gender TikTok } \\
\hline & & Male & Female & $\begin{array}{c}\text { Value } \\
\text { (sig. }-d f)^{*}\end{array}$ & Male & Female & $\begin{array}{c}\text { Value } \\
(\text { sig. }-d f)^{*}\end{array}$ \\
\hline \multirow[t]{3}{*}{ Factor 1. Social } & Low & $368(77.3 \%)$ & $520(80.2 \%)$ & & $235(77.3 \%)$ & $292(80.9 \%)$ & \\
\hline & Medium & $63(13.2 \%)$ & $75(11.6 \%)$ & $\begin{array}{c}1.428 \\
(0.490 ; 2)\end{array}$ & $43(14.1 \%)$ & $40(11.1 \%)$ & $\begin{array}{c}1.563 \\
(0.458 ; 2)\end{array}$ \\
\hline & High & $45(9.5 \%)$ & $53(8.2 \%)$ & & $26(8.6 \%)$ & $29(8.0 \%)$ & \\
\hline \multirow[t]{3}{*}{ Factor 2. Authenticity } & Low & $146(30.7 \%)$ & $196(30.2 \%)$ & & $74(24.3 \%)$ & $95(26.3 \%)$ & \\
\hline & Medium & $267(56.1 \%)$ & $383(59.1 \%)$ & $\begin{array}{c}2,011 \\
(0.366 ; 2)\end{array}$ & $96(31.6 \%)$ & $103(28.5 \%)$ & $\begin{array}{c}0,808 \\
(0.668 ; 2)\end{array}$ \\
\hline & High & $63(13.2 \%)$ & $69(10.6 \%)$ & & $134(44.1 \%)$ & $163(45.2 \%)$ & \\
\hline \multirow[t]{3}{*}{ Factor 3. Control } & Low & $300(63.0 \%)$ & $393(60.6 \%)$ & & $190(62.5 \%)$ & $207(57.3 \%)$ & \\
\hline & Medium & $121(25.4 \%)$ & $187(28.9 \%)$ & $\begin{array}{c}1,717 \\
(0.424 ; 2)\end{array}$ & $77(25.3 \%)$ & $114(31.6 \%)$ & $\begin{array}{c}3,150 \\
(0.207 ; 2)\end{array}$ \\
\hline & High & $55(11.6 \%)$ & $68(10.5 \%)$ & & $37(12.2 \%)$ & $40(11.1 \%)$ & \\
\hline
\end{tabular}

Note: Instagram $\mathrm{N}=1.124$; TikTok $\mathrm{N}=665 ;{ }^{*} \chi^{2}$ 


\section{DISCUSSION AND CONCLUSIONS}

One of the main outcomes of this study is that self-presentation practices could be less guided by social feedback than expected because the number of followers or likes did not matter for most adolescents, according to the evidence obtained in relation to Factor 1 for Instagrammers and TikTokers. The possibilities of comparing social status, although characteristic on both social networks, become less important, perhaps because, in line with other studies, such quantitative measures lose their attraction for the younger generations, who see person-specific effects linked to friendship and closeness as the most relevant factor (Davis, 2014; Pouwels, Valkenburg, Beyens, Van Driel, \& Keijsers, 2021). Adolescents do continue to factor in the perspectives of their audiences and the need for peer approval of online self-presentations (Yau \& Reich, 2019); however, further research is needed on the value that adolescents assign to these social parameters over other more qualitative ones, since some studies confirm that Likes increase self-acceptance (Cipolletta, Malighetti, Cenedese, \& Spoto, 2020), and that the risks focused especially on vulnerable adolescents, for whom collecting fewer likes could become problematic (H. Y. Lee et al., 2020). This matches traditional identity theories, which highlight the importance of identity confirmation by others (Davis, 2014) and the ideas of identity in interaction built from the desired sense of belonging to a group (Eek-Karlsson, 2021; Mclay \& Renshaw, 2019) .

Regarding conformity in self-presentation practices, the other two factors obtained (authenticity and image control), confirm the initial theories of online identity in adolescence and the need for self-consistency (Davis, 2014). This is in line with other studies where it became clear that adolescents must walk a fine line between authenticity and enhancing the self to create a good impression Calvin (2020). In our study, adolescents tended to be guided by innovative predispositions of truthfulness (not hiding the real self) due not only to the lower levels found in the control image factor but also for the medium and higher levels obtained for the authenticity factor. The achievement of this result was found in all age ranges and for both genders, with slight differences such as the more realistic approach by females, inviting us to think of this as a cultural trend, since other studies have also reported higher percentages of truthfulness in adolescents' profiles (Dilon, 2020). When replicating the factorial analysis, the similar factors and percentages found among self-presentation practices could also indicate cultural tendencies to perform analogously within different SN platforms, regardless of the technological affordances offered. However, differences in regard to the authenticity factor provide weight to the importance of contextual conditions and SN possibilities (Mclay \& Renshaw, 2019), which explains why medium percentages were found on Instagram, where filters to change or improve self-recognition are typically performed. Instead, TikTok shows higher percentages, since the use of videos cannot easily offer misrecognition. In this vein, if SN features and affordances acquire relevance for constructing and varying the trajectories for youth identity development (Calvin, 2020; Vidales-Bolaños \& Sádaba, 2017) because of the enhancement - or not - of authentic self-representation, much attention needs to be placed on the digital competences gained by adolescents and their self-efficacy, either to take advantage of the impression management, the likeability (Hong et al., 2020) and the continuous editability offered (Ditchfield, 
2020), along with the chance to understand how to use risk prevention techniques when they present themselves using real data that could be misused and leave them unprotected. Some related studies with Instagram and TikTok have started to evidence several consequences; the study by Torrecillas-Lacave et al. (2020) found that less than half of adolescents know how to change preferences or set a high level of privacy by filtering audiences; Dilon (2020) warned about how the time spent on TikTok is creating a gap between poorly literate technology users and highly literate ones; Fondevila-Gascón et al. (2020), observed that Instagram affordances generate unreal expectations among adolescents about what practices can serve to avoid possible negative outcomes of self-exposure; Jaffar and Riaz (2020) concluded that more actions should be taken to defend TikTok users against misapplication as well as to protect their privacy and digital security.

More evidence needs to be gathered to confirm the extent to which the younger generations are guided by authenticity (telling the truth about themselves) or, on the contrary, continuing to have several profiles, presenting their self-image(s) in different ways on SN platforms. Our study revealed inconsistent data in this area, even when anonymity was guaranteed. In this and other studies (e.g. Huang, \& Su, 2018; Yau \& Reich, 2019; Ramos-Soler et al., 2019), a number of research questions generate extreme lower percentages around impersonation and moderate ones for truthfulness.

As a limitation of this study, since the sample was collected after the lockdown, and consequently affected by Covid-19 social distancing restrictions, this situation probably increases the screen time and, thus, the intensive use of SNs. During the pandemic in Spain, TikTok and Instagram have become increasingly popular among young people who probably increased the practices for identity expression and narrative online, varying expected tendencies for early adolescence or specific patterns more often found for females. Replication of data with further samples or countries becomes necessary and important, as habits and behaviours intensively learned or rapidly habituated online to cope in the course of an ongoing pandemic are yet to be fully understood.

Our study found at least three profiles with motives for the self-representation on SNs, guided by authenticity, by image control or by social approval. However, the younger generations have now become multiusers of several SNs, learning to take advantage of specific technological affordances to adjust their self-presentation practices. Thus, more empirical work, both of an exploratory and a confirmatory nature, is needed to classify predictors for self-presentation in different digital spaces, along with the correlational effects of taking risks related to dissimilar ways of self-presentation.

\section{ACKNOWLEDGEMENTS}

This paper is framed on project: "CONECTID: Hyperconnected identity of young people and their perception of time in digital pastimes" funded by MCIN/AEI/FEDER

Funded by: Spanish State Research Agency, Spain

Funder Identifier: http://dx.doi.org/10.13039/501100011033

Award: PGC2018-097884-B-I00 


\section{REFERENCES}

Albarello, F., Crocetti, E., \& Rubini, M. (2018). I and us: A longitudinal study on the interplay of personal and social identity in adolescence. Journal of youth and adolescence, 47(4), 689-702. https://doi.org/10.1007/s10964-017-0791-4

Arriaga, A., Marcellán, I., \& Reyes, M. (2016). Las redes sociales: espacios de participación y aprendizaje para la producción de imágenes digitales de los jóvenes. Estudios sobre educación, 30, 197-216. https://doi.org/10.15581/004.30.197-216

Bell, B. T. (2019). You take fifty photos, delete forty-nine and use one: A qualitative study of adolescent image-sharing practices on social media. International Journal of Child-Computer Interaction, 20, 64-71. https://doi.org/10.1016/j.ijcci.2019.03.002

Boyd, D. (2007). Why youth heart social network sites: the role of networked publics in teenage social life. Youth, Identity and Digital Media (pp. 119-142). MIT Press.

Brailovskaia, J., Schillack, H., \& Margraf, J. (2020). Tell me why are you using social media (SM)! Relationship between reasons for use of SM, SM flow, daily stress, depression, anxiety, and addictive SM use-An exploratory investigation of young adults in Germany. Computers in Human Behavior, 113, 106511. https://doi.org/10.1016/j.chb.2020.106511

Calvin, A. J. (2020). Online Self-Presentation in Adolescence. The International Encyclopedia of Media Psychology, 1-10. https://doi.org/10.1002/9781119011071.iemp0288

Carpenter, J. P., Morrison, S. A., Craft, M., \& Lee, M. (2020). How and why are educators using Instagram? Teaching and teacher education, 96, 103149-103149. https://doi.org/10.1016/ j.tate.2020.103149

Cipolletta, S., Malighetti, C., Cenedese, C., \& Spoto, A. (2020). How Can Adolescents Benefit from the Use of Social Networks? The iGeneration on Instagram. International Journal of Environmental Research and Public Health, 17(19). https://doi.org/10.3390/ijerph17196952

Crocetti, E., Rubini, M., Branje, S., Koot, H. M., \& Meeus, W. (2016). Self-concept clarity in adolescents and parents: A six-wave longitudinal and multi-informant study on development and intergenerational transmission. Journal of Personality, 84(5), 580-593. https://doi.org/ 10.1111 jopy. 12181

Datareportal. (2021). Digital 2021. Global Overview Report. Retrieved from https://bit.ly/2UgoniH

Davis, K. (2013). Young people's digital lives: The impact of interpersonal relationships and digital media use on adolescents' sense of identity. Computers in Human Behavior, 29(6), 2281-2293. https://doi.org/10.1016/j.chb.2013.05.022

Davis, K. (2014). Youth Identities in a Digital Age: The Anchoring Role of Friends in Young People's Approaches to Online Identity Expression. Mediated Youth Cultures (pp. 11-25). Springer. https://doi.org/10.1057/9781137287021_2n

Dilon, C. (2020). Tiktok Influences on Teenagers and Young Adults Students: The Common Usages of the Application Tiktok. American Scientific Research Journal for Engineering, 68(1), 23134402.

Ditchfield, H. (2020). Behind the screen of Facebook: Identity construction in the rehearsal stage of online interaction. New Media \& Society, 22(6), 927-943. https://doi.org/10.1177/ 1461444819873644

Eek-Karlsson, L. (2021). The Importance of Belonging: A Study About Positioning Processes in Youths' Online Communication. SAGE Open, 11(1). https://doi.org/10.1177/ 2158244020988860

Erikson, E. H. (1959). Identity and the life cycle: Selected papers. Psychological Issues, 1, 1-171.

Fondevila-Gascón, J., Gutiérrez-Aragón, O., Copeiro, M., Villalba-Palacín, V., \& Polo-López, M. (2020). Influence of Instagram stories in attention and emotion depending on gender. Comu- 
nicar, 63, 41-50. https://doi.org/10.3916/C63-2020-04

García-Umaña, A., \& Tirado-Morueta, R. (2018). Digital Media Behavior of School Students: Abusive Use of the Internet. Journal of New Approaches in Educational Research, 7(2), 140-147. https://doi.org/10.7821/naer.2018.7.284

Gee, J. P. (1999). An introduction to discourse analysis: Theory and methods. Routledge.

Goffman, E. (1959). The Presentation of Self in Everyday Life. Anchor Books.

Hair, J. F., Anderson, R. E., Tatham, R. L., \& Black, W. C. (1999). Multivariate data analysis. PrenticeHall International.

Herring, S. C., \& Kapidzic, S. (2015). Teens, gender, and self-presentation in social media. International encyclopedia of social and behavioral sciences (Vol. 2, pp. 1-16). Retrieved from https://bit.ly/3gy1W1q

Hong, S., Jahng, M. R., Lee, N., \& Wise, K. R. (2020). Do you filter who you are?: Excessive selfpresentation, social cues, and user evaluations of Instagram selfies. Computers in Human Behavior, 104. https://doi.org/10.1016/j.chb.2019.106159

Huang, Y. T., \& Su, S. F. (2018). Motives for Instagram Use and Topics of Interest among Young Adults. Future Internet, 10(8). https://doi.org/10.3390/fi10080077

Jaffar, B. A., \& Riaz, S. (2020). Living in a Moment: Impact of TikTok on Influencing Younger Generation into Micro-Fame. Journal of Content, Community \& Communication, 10, 187194. https://doi.org/10.31620/jccc.12.19/19

Kay, A. (2018). Erikson Online: Identity and Pseudospeciation in the Internet Age. Identity. An International Journal of Theory and Research, 18(4), 264-273.

Lázaro-Niso, R. (2020). La red social TikTok y su integración en el aula de literatura: propuestas didácticas. In E. López-Meneses et al. (Eds.), Claves para la innovación pedagógica ante los nuevos retos. Respuestas en la vanguardia de la práctica educativa (pp. 3587-3597). Octaedro. Retrieved from https://bit.ly/3gwnMlJ

Lee, E., Lee, J. A., Moon, J. H., \& Sung, Y. (2015). Pictures Speak Louder than Words: Motivations for Using Instagram. Cyberpsy., Behavior, and Soc. Networking, 18, 552-556. https://doi.org/ 10.1089/cyber.2015.0157

Lee, H. Y., Jamieson, J. P., Reis, H. T., Beevers, C. G., Josephs, R. A., Mullarkey, M. C., ... Yeager, D. S. (2020). Getting fewer "likes" than others on social media elicits emotional distress among victimized adolescents. Child Development, 91(6), 2141-2159. https://doi.org/10.1111/cdev .13422

López-Aguado, M., \& Gutiérrez-Provecho, L. (2019). Com dur a terme i interpretar una anàlisi factorial exploratòria utilitzant spss. REIRE Revista d'Innovació i Recerca en Educació, 12(2), 1-14. https://doi.org/10.1344/reire2019.12.227057

Lorenzo-Seva, U., \& Ferrando, P. J. (2013). FACTOR 9.2: A comprehensive program for fitting exploratory and semiconfirmatory factor analysis and IRT models. Applied Psychological Measurement, 37(6), 497-498. https://doi.org/10.1177/0146621613487794

Malo-Cerrato, S., Martín-Perpiñá, M., \& Viñas-Poch, F. (2015). Excessive use of social networks: Psychosocial profile of Spanish adolescents. Comunicar, 56, 101-110. https://doi.org/10.3916/ C56-2018-10

Marcelino, G. (2015). Migración de los jóvenes españoles en redes sociales, de Tuenti a Facebook y de Facebook a Instagram. La segunda migración. Revista Científica de Comunicación y Tecnologías Emergentes, ICONO14, 14, 48-72. https://doi.org/10.7195/ri14.v13i2.821

Marcia, J. E. (2002). Identity and psychosocial development in adulthood. An International Journal of Theory and Research, 2, 7-28. https://doi.org/10.1207/S1532706XID0201_02

Mascheroni, G., Vincent, J., \& Jimenez, E. (2015). Girls are addicted to likes so they post semi-naked selfies: Peer mediation, normativity and the construction of identity online. Cyberpsychology: 
Journal of Psychosocial Research on Cyberspace, 9(1). https://doi.org/10.5817/CP2015-1-5

Mcdonald, R. P. (2005). Semiconfirmatory factor analysis: The example of anxiety and depression. Structural Equation Modeling, 12, 163-172. https://doi.org/10.1207/s15328007sem1201_9

Mclay, K. F., \& Renshaw, P. D. (2019). Making 'us' visible: Using membership categorization analysis to explore young people's accomplishment of collective identity-in-interaction in relation to digital technology. British Educational Research Journal, 46(1), 44-57. https:/doi.org/ 10.1002/berj.3565

Muñoz-Rodríguez, J. M., Fincias, P. T., González, S. S., \& Hueso, A. (2020). Entornos digitales, conectividad y educación. Percepción y gestión del tiempo en la construcción de la identidad digital de la juventud. Revista Española de Pedagogía, 78(277), 457-476. https://doi.org/ 10.22550/REP78-3-2020-07

Nunnally, J. C., \& Bernstein, I. H. (1994). Psychometric Theory (3rd ed.). McGraw-Hill.

Omarzu, J. (2000). A Disclosure Decision Model: Determining How and When Individuals Will Self-Disclose. Personality and Social Psychology Review, 4(2), 174-185. https://doi.org/10 .1207/S15327957PSPR0402_05

Pouwels, J. L., Valkenburg, P. M., Beyens, I., Van Driel, I. I., \& Keijsers, L. (2021). Social media use and friendship closeness in adolescents' daily lives: An experience sampling study. Developmental Psychology, 57(2), 309-323. https://doi.org/10.1037/dev0001148

Prades, M., \& Carbonell, X. (2016). Motivaciones sociales y psicológicas para usar Instagram. Communication Papers - Media Literacy \& Gender Studies, 5(9), 27-36.

Ramos-Soler, I., Martínez-Sala, A. M., \& Campillo-Alhama, C. (2019). ICT and the Sustainability of World Heritage Sites. Sustainability, 11(11), 3203-3203.

Scott, G. G., \& Fullwood, C. (2020). Does recent research evidence support the hyperpersonal model of online impression management? . Current Opinion in Psychology, 36, 106-111. https://doi.org/10.1016/j.copsyc.2020.05.005

Statista. (2021). Porcentaje de niños de entre 4 y 15 años usuarios en redes sociales en España en 2020. Retrieved from https://bit.ly/3vxDfWT

Ting, H., Wong, W., Run, S. D., \& Choo, S. (2015). Beliefs about the Use of Instagram: An Exploratory Study. International Journal of Business and Innovation, 2(2).

Torrecillas-Lacave, T., Vázquez-Barrio, T., Suárez, R., \& Fernández-Martínez, L. M. (2020). El papel de los padres en el comportamiento online de menores hiperconectados. Revista Latina de Comunicación Social, 75, 121-178. https://doi.org/10.4185/RLCS-2020-1419

Valkenburg, P. M., \& Peter, J. (2011). Online communication among adolescents: An integrated model of its attraction, opportunities, and risks. Journal of adolescent health, 48(2), 121-127. https://doi.org/10.1016/j.jadohealth.2010.08.020

Vidales-Bolaños, M., \& Sádaba, C. (2017). Connected teens: Measuring the impact of mobile phones on social relationships through social capital. Comunicar, 53, 19-28. https://doi.org/10.3916/ C53-2017-02

WeAreSocial. (2021). Digital, 2021. Retrieved from https://wearesocial.com/digital-2021

Yang, C. C., Holden, S. M., \& Carter, M. D. (2018). Social media social comparison of ability (but not opinion) predicts lower identity clarity: Identity processing style as a mediator. Journal of youth and adolescence, 47(10). https://doi.org/10.1007/s10964-017-0801-6

Yau, J. C., \& Reich, S. M. (2019). It's Just a Lot of Work: Adolescents' Self-Presentation Norms and Practices on Facebook and Instagram. Journal of research on adolescence, 29(1), 196-209. https://doi.org/10.1111/jora.12376

Zuo, H., \& Wang, T. (2019). Analysis of Tik Tok User Behavior from the Perspective of Popular Culture. Frontiers in Art Research, 1(3), 1-05. https://doi.org/10.25236/FAR.20190301 